\title{
Pattern of Knee Injury Cases Attending Combined Military Hospital, Dhaka
}

\author{
Rahman $\mathrm{MM}^{1}$, Rahman $\mathrm{MF}^{2}$, Amin $\mathrm{ZA}^{3}$, Faiza $\mathrm{ZH}^{4}$, Islam $\mathrm{Z}^{5}$, Islam $\mathrm{MZ}^{6}$
}

DOI: https://doi.org/10.3329/jafmc.v15i1.48656

\begin{abstract}
Introduction: Knee injury one of the most common injuries among soldiers accounts for losses in efficient combat power as well as increase burden of disability placed to the different units of Armed Forces.
\end{abstract}

Objectives: To find out the pattern of knee injury of patients attending at a tertiary military hospital.

Materials and Methods: This descriptive cross-sectional study carried out during January 2017 to December 2017 at Orthopedic Center of $\mathrm{CMH}$, Dhaka. A total of 153 knee injuries patients were selected purposively as per selection criteria and data were collected by face to face interview and record review.

Results: Total 153 respondents' mean age was $31.03 \pm 10.19$ years, most of them (41.8\%) were from age group 25-34 years and were male (90.8\%). Anterior Cruciate Ligament (ACL) injury was predominant $(37.9 \%)$ and main precipitating physical event was football (20.3\%) followed by jumping 9 feet ditch (16.3\%). Right knee was more involved (49.7\%) than left knee (46.4\%). Most of injuries occurred in the exercise ground $(40.5 \%)$ then sports ground $(35.3 \%)$. ACL injuries (19\%) were common in the age group 25-34 years and 9.8\% were in 15-24 years. Morbidity duration of knee injuries was $<1$ year for $49 \%$ and $1-5$ years for $36.6 \%$ of the respondents.

Conclusion: Training-related injuries negatively impact the capabilities of any Armed Forces. Low fitness levels among soldiers are associated with increased risk for injury and attrition. Knee injury may be considered as one of the major occupational health problems of Armed Forces.

Key-words: Knee injury, Anterior cruciate ligament, Soilders, Physical events, Training, Sports.

\section{Introduction}

Knee pain accounts for approximately one third of musculoskeletal problem seen in primary health care settings. This complaint is most prevalent in physically active patients, with as many as 54 percent of athletes having some degree of knee pain each year. Knee pain can be a source of significant disability, restricting the ability to work or perform activities of daily living ${ }^{1}$. The knee is one of the most frequently injured joints in the human body and it is commonly injured during sporting activities. Among knee injuries, the Anterior Cruciate Ligament (ACL) is one of the most frequently disrupted ligaments in the $\mathrm{knee}^{2}$. Knee injury can be devastating to a young athlete, with the potential loss of sports participation and a significantly greater risk of developing knee osteoarthritis $(\mathrm{OA})$ in the long term ${ }^{3}$.

Muscles and ligaments are normally exposed to stress through the life. Their structures are such that respond and adapt to the usual amount of the stress exposure. Damage occurs when the muscles or connective tissue is exposed to higher than the usual stress levels. This can be single, sudden excessive stress, or the result of repetitive stress to the muscle or ligament. In either case, the physician or the health care person must determine the magnitude of the problem and ascertain the possible stress involve to make appropriate intervention measures to care the injury and to prevent the recurrence ${ }^{4}$.

The knee is commonly injured because of its delicate anatomical structure where share placement in maximum weight bearing as well as opposing force encountered on the ground during activities like games and sports, physical efficiency test, various un adapting training activities in the Armed Forces like assault bayonet fighting, unarmed combat, organized drill and parade etc. The menisci and the ligaments of the knee are commonly injured due to damaging force which is a combined rotation and impact injury to bent weight bearing knee, though at times a direct physical force to a flexed knee is also responsible. Knee injuries are often severely disabling unless diagnosed and managed properly.

\section{Materials and Methods}

This was a descriptive cross sectional study carried out to find out the characteristics of knee Injury patients attending at Orthopedic Center of $\mathrm{CMH}$, Dhaka. The study was conducted from January 2017 to December 2017. A total of 153 knee injuries patients were selected by purposive method of sampling. As per the selection criteria of the study, data collection was carried out through face to face interview by asking questions in Bangla and record review. Data compilation was done by IBM SPSS Statistics version 19 software. The study population was all the patients with knee injuries attending for treatment at Orthopedic Center of $\mathrm{CMH}$, Dhaka. Patients of Armed Forces (e.g. Army, Navy and Air Force) treated as OPD and IPD cases in this hospital, including referred cases from peripheral CMHs. Commissioned Officers, Junior Commissioned Officers, Non Commissioned Officers, Sainik or equivalent rank from different units of Army, Navy, Air Force and entitled civil patients were included in the study.

1. Maj Md Mashiur Rahman, MBBS, MPH, GSO-2 Coord, AFMC, Dhaka (E-mail: dr.sipon@gmail.com) 2. Maj Gen Md Fashiur Rahman, SPP, ndc, MBBS, MPH, FCGP, MBA, MSS, LLB, PhD Fellow, Director General of Medical Services, Bangladesh Armed Forces 3. Brig Gen Zulfiquer Ahmed Amin, MBBS, MPH, MPhil, Deputy DGMS, Bangladesh Armed Forces 4. Dr Zakia Hossain Faiza, MBBS, Medical Officer 5. Maj Zahidul Islam, MBBS, MPH, DAA\&QMG (Admin), AMCC\&S, Ghatail 6. Maj Md Zahirul Islam, MBBS, MPH, DADMS (Coord), Medical Directorate, Army Headquarters, Dhaka. 
Inclusion criteria of research sample included patients of Armed Forces attending the Orthopedic Center of $\mathrm{CMH}$, Dhaka for treatment of knee injuries, old and new cases of knee injury, reporting to OPD and/or got admitted during the data collection period, knee injuries diagnosed by the concerned orthopedic surgeon, willing to participate. Any injury other than knee, unwilling to participate as research sample was excluded. The study was conducted maintaining all kinds of ethical consideration. Formal approval of the study was obtained followed by ethical clearance was taken from the ethical committee of concerned authority. Informed verbal consent of the respondents was obtained before data collection by explaining the purpose of the study, duration of the interview, risks and the benefits for participation in the study. Information of the participants was kept confidential and will not be used for any other purpose except research.

\section{Results}

Out of 153 respondents, $90.80 \%$ were male and $9.20 \%$ were female and mean \pm SD age was $31.03 \pm 10.19$ years. Majority $(41.8 \%)$ of the respondents were in the age group of 25-34 years, followed by $30.1 \%, 17 \%, 7.2 \%$ and $3.9 \%$ in the age group $15-24$, $35-44,45-54$ and $>55$ years respectively. For ACL injury, majority (19\%) belonged to age group 25-34 years (Table-I). About a fifth $(20.3 \%)$ of the respondents received injury while playing football; other precipitating events were, by jumping 9 feet ditch (16.3\%), assault course/bayonet fighting (12.4\%), imbalance landing $(9.8 \%)$, direct hit by object $(8.5 \%)$, slipping on smooth surface $(7.8 \%)$, falling from height $(7.2 \%)$, playing volleyball $(6.5 \%)$, running $(6.5 \%)$ and playing basketball (4.6\%) (Table-II). Almost half $(49.7 \%)$ of the knee injuries involved the right knee followed by left knee (46.4\%) and both knees (3.9\%) (Table-II). Most of the knee injuries $(40.5 \%)$ occurred at exercise ground, followed by at sports ground $(35.3 \%)$ and road $(9.2 \%)$. Most of the ACL injury occurred (17\%) at sports ground and (15.7\%) at exercise ground (Table-III). Almost half of the respondents with knee injuries (49\%) suffered from the condition for less than one year and duration between $1-5$ years $(36.6 \%)$ and $14.4 \%$ for more than 5 years. As type of knee injuries, majority of the respondents with $A C L$ injury suffered for a duration less than one year (16.3\%) (Table-IV).

Table-I: Distribution of types of knee injuries by age group $(n=153)$

\begin{tabular}{|l|c|c|c|c|c|c|}
\hline \multirow{3}{*}{ Type of knee injuries } & \multicolumn{5}{|c|}{ Age group } & \multirow{2}{*}{$\begin{array}{c}\text { Total } \\
\mathrm{n}(\%)\end{array}$} \\
\cline { 2 - 6 } & $\begin{array}{c}15-24 \\
\mathrm{n}(\%)\end{array}$ & $\begin{array}{c}25-34 \mathrm{n} \\
(\%)\end{array}$ & $\begin{array}{c}35-44 \\
\mathrm{n}(\%)\end{array}$ & $\begin{array}{c}45-54 \\
\mathrm{n}(\%)\end{array}$ & $\begin{array}{c}>55 \\
\mathrm{n}(\%)\end{array}$ & \\
\hline Sprain/Contusion & $7(4.6)$ & $7(4.6)$ & $3(2.0)$ & $2(1.3)$ & - & $19(12.4)$ \\
\hline ACL injury & $15(9.8)$ & $29(19.0)$ & $7(4.6)$ & $5(3.3)$ & $2(1.3)$ & $58(37.9)$ \\
\hline ACL with MM injury & $6(3.9)$ & $08(5.2)$ & $3(2.0)$ & $1(0.7)$ & $1(0.7)$ & $19(12.4)$ \\
\hline ACL with MM \& MCL injury & $3(2.0)$ & $6(3.9)$ & $2(1.3)$ & - & $1(0.7)$ & $12(7.8)$ \\
\hline PCL injury & - & $2(1.3)$ & $2(1.3)$ & - & - & $4(2.6)$ \\
\hline Meniscus injury & $4(2.6)$ & $7(4.6)$ & $2(1.3)$ & $2(1.3)$ & $1(0.7)$ & $16(10.5)$ \\
\hline Traumatic synovitis & $4(2.6)$ & $2(1.3)$ & $2(1.3)$ & - & - & $8(5.2)$ \\
\hline IDK & $3(2.0)$ & $1(0.7)$ & $1(0.7)$ & - & $1(0.7)$ & $6(3.9)$ \\
\hline Patellar fracture/dislocation & - & - & $2(1.3)$ & $1(0.7)$ & - & $3(2.0)$ \\
\hline Quadriceps muscles strain & $1(0.7)$ & $1(0.7)$ & $1(0.7)$ & - & - & $3(2.0)$ \\
\hline MCL injury & $3(2.0)$ & $1(0.7)$ & $1(0.7)$ & - & - & $5(3.3)$ \\
\hline Total & $46(30.1)$ & $64(41.8)$ & $26(17.0)$ & $11(7.2)$ & $6(3.9)$ & $153(100)$ \\
\hline
\end{tabular}

Table-ll: Distribution of respondents by nature of precipitating events and knee joint injured $(n=153)$

\begin{tabular}{|c|l|c|c|}
\hline \multicolumn{2}{|c|}{ Characteristics } & Frequency & Percentage \\
\hline \multirow{4}{*}{ Nature of events } & Football & 31 & 20.3 \\
\cline { 2 - 4 } & Volleyball & 10 & 6.5 \\
\cline { 2 - 4 } & Basketball & 7 & 4.6 \\
\cline { 2 - 4 } & Assault course/bayonet fighting & 19 & 12.4 \\
\cline { 2 - 4 } & Slipping on smooth surface & 12 & 7.8 \\
\cline { 2 - 4 } & Direct hit by object & 13 & 8.5 \\
\cline { 2 - 4 } & Imbalance landing & 15 & 9.8 \\
\cline { 2 - 4 } & Jump 9 feet ditch & 25 & 16.3 \\
\cline { 2 - 4 } Knee joint injured & Falling & 11 & 7.2 \\
\cline { 2 - 4 } & Runs & 10 & 6.5 \\
\cline { 2 - 4 } & Right knee & 76 & 49.7 \\
\cline { 2 - 4 } & Left knee & 71 & 46.4 \\
\hline & Both knee & 6 & 3.9 \\
\hline
\end{tabular}

Table-III: Distribution of types of knee injuries by the places of occurrence $(n=153)$

\begin{tabular}{|c|c|c|c|c|c|c|}
\hline \multirow[t]{2}{*}{ Types of knee injuries } & \multicolumn{6}{|c|}{ Place of injury occurrence } \\
\hline & 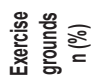 & 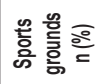 & 䚻 쁭 & 홍 & 营 & 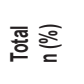 \\
\hline Sprain/Contusion & $4(2.6)$ & $5(3.3)$ & $1(0.7)$ & $5(3.3)$ & $4(2.6)$ & $19(12.4)$ \\
\hline ACL injury & $24(15.7)$ & $26(17.0)$ & $2(1.3)$ & $5(3.3)$ & $1(0.7)$ & $58(37.9)$ \\
\hline ACL with MM injury & $11(7.2)$ & $5(3.3)$ & $2(1.3)$ & $1(0.7)$ & - & $19(12.4)$ \\
\hline ACL with MM \& MCL injury & $6(3.9)$ & $3(2.0)$ & $2(1.3)$ & - & $1(0.7)$ & $12(7.8)$ \\
\hline PCL injury & $1(0.7)$ & $3(2.0)$ & - & - & - & $4(2.6)$ \\
\hline Meniscus injury & $7(4.6)$ & $5(3.3)$ & $2(1.3)$ & - & $2(1.3)$ & $16(10.5)$ \\
\hline Traumatic synovitis & $3(2.0)$ & $1(0.7)$ & $1(0.7)$ & - & $3(2.0)$ & $8(5.2)$ \\
\hline IDK & $3(2.0)$ & $3(2.0)$ & - & - & - & $6(3.9)$ \\
\hline Patellar fractureldislocation & - & $1(0.7)$ & . & - & $2(1.3)$ & $3(2.0)$ \\
\hline Quadriceps muscles strain & $2(1.3)$ & - & $1(0.7)$ & - & - & $3(2.0)$ \\
\hline MCL injury & $1(0.7)$ & $2(1.3)$ & $1(0.7)$ & - & $1(0.7)$ & $5(3.3)$ \\
\hline Total & $62(40.5)$ & $54(35.3)$ & $12(7.8)$ & $11(7.2)$ & $14(9.2)$ & $153(100)$ \\
\hline
\end{tabular}

Table-IV: Distribution of types of knee injuries by duration of morbidity $(n=153)$

\begin{tabular}{|l|c|c|c|c|}
\hline \multirow{2}{*}{ Types of knee injuries } & \multicolumn{3}{|c|}{ Duration of morbidity } & \multirow{2}{*}{$\begin{array}{c}\text { Total } \\
\end{array}$} \\
\cline { 2 - 4 } & $<1 \mathrm{yr}$ & $\mathbf{1}$ to 5 yrs & $>5$ yrs & \\
\hline Sprain/contusion & $18(11.8)$ & $1(0.7)$ & - & $19(12.4)$ \\
\hline ACL injury & $25(16.3)$ & $22(14.4)$ & $11(7.2)$ & $58(37.9)$ \\
\hline ACL with MM injury & $6(3.9)$ & $10(6.5)$ & $3(2.0)$ & $19(12.4)$ \\
\hline ACL with MM \& MCL injury & $2(1.3)$ & $7(4.6)$ & $3(2.0)$ & $12(7.8)$ \\
\hline PCL injury & - & $3(2.0)$ & $1(0.7)$ & $4(2.6)$ \\
\hline Meniscus injury & $6(3.9)$ & $8(5.2)$ & $2(1.3)$ & $16(10.5)$ \\
\hline Traumatic synovitis & $8(5.2)$ & - & - & $8(5.2)$ \\
\hline IDK & $3(2.0)$ & $2(1.3)$ & $1(0.7)$ & $6(3.9)$ \\
\hline Patellar fracture/dislocation & $1(0.7)$ & $1(0.7)$ & $1(0.7)$ & $3(2.0)$ \\
\hline Quadriceps muscles strain & $3(2.0)$ & - & & $3(2.0)$ \\
\hline MCL injury & $3(2.0)$ & $2(2.0)$ & & $5(3.3)$ \\
\hline Total & $75(49)$ & $56(36.6)$ & $22(14.4)$ & $153(100)$ \\
\hline
\end{tabular}




\section{Discussion}

In this study, age range of the respondents was 15 to 60 years. Majority $(41.8 \%)$ of the respondents belonged to the age group 25-34 years followed by age group 15-24 years (30.1\%). A study at $\mathrm{CMH}$, Dhaka found that all cases of knee injury belonged to the age group between 18 and 36 years 5 . In a similar study conducted at Command Hospital Pune and Military Hospital Kirke Complex, India, it was observed that $56 \%$ of the cases belonged to $25-35$ year age group ${ }^{6}$. Most common type of knee injury was ACL injury (37.9\%), followed by combined ACL with medial meniscus injury (12.4\%), Sprain/Contusion (12.4\%), Meniscus injury (10.5\%), the least was observed in case of Patellar fracture/dislocation and Quadriceps muscles strain (2\%). A study conducted at $\mathrm{CMH}$, Dhaka had shown that traumatic synovitis was the most frequently occurred knee injuries (64.29\%), followed by Medial meniscus injury $(19.05 \%)^{7}$. This did not confer with the finding of present study. The difference may be due to small sample size and limited diagnostic facilities available in the past and the differences in the nature of physical activities in the study population. In a cross sectional study on 205 cases at Orthopedic Center of CMH, Dhaka (March to May 2005); found that majority $(68.5 \%)$ of injuries involved ACL contusion $(09.1 \%)^{8}$. This finding is almost similar with the present study results.

The occurrence of knee injury usually varies with nature of physical activity, place and environment, pre-training exposure and also protective measure adopted by the individual. The study had shown that more than one third $(40.5 \%)$ of the respondents of Armed Forces sustained knee injury at the exercise ground, followed at sports ground (35.3\%). In a study among the serving soldiers reporting sick for knee injury at $\mathrm{CMH}$, Dhaka; found that 91.3\% knee injuries took place at training and sports ground ${ }^{9}$. Another study in the same place, showed that Sports ground was the place where maximum injuries of all types occurred, such as knee injury in $34.9 \%$ of cases, foot in $32 \%$, fore arm in $18.2 \%$ followed by training ground, amounting to knee injury in $23.3 \%$, foot in $20 \%$ and forearm in $24.2 \%{ }^{10}$. Soldiers of Armed Forces are regularly exposed to physical training activity and at times with rigorous physical training like commando course, assault course etc. conducted at training ground which put maximum risk of knee injury to the soldiers. Therefore frequency of knee injury were more in the training ground than in sports ground.

The numerous health benefits of the physical activity like exercise, training activity and sports have been well documented but physical activities as training and sports also have corresponding risk to knee injuries. In this study more than a fourth (28.7\%) of the respondents received knee injury as a result of special training events like assault course/bayonet fighting and jumping 9 feet ditch collectively. The other injuries were due to contact and non-contact stress football was the main event of injury accounted for $(20.3 \%)$, it was followed by volleyball $(6.5 \%)$, basketball $(4.6 \%)$, direct hit by object $(8.5 \%)$, slipping on smooth surface $(7.8 \%)$, imbalance landing $(9.8 \%)$, falling $(7.2 \%)$ and runs (6.5\%). In a similar study at CMH, Dhaka (April 1990 to August 1996) had revealed that out of 68 cases, contact and non-contact stress accounted for $67.14 \%$; football was the main event of injury accounted for $40 \%$, followed by volleyball $(18.57 \%)$, basketball
(8.57\%), jumping 9 feet ditch was (12.86\%), assault/bayonet fighting accounted for $(4.29 \%)$ and direct hit by object $(1.43 \%)^{9}$. The result was almost consistent with the present study.

Depending on the use of knee with its coordinated movement characteristic with the leg and feet, impact of stress also varies. Moreover, it depends on individual use of knee according to the nature of physical activities. In present study with respondents of knee injuries, right knee involvement was $49.7 \%$, a slight higher than the left knee which was $46.4 \%$. Another study carried at $\mathrm{CMH}$, Dhaka on knee injury, had found that right sided knee injury was about 1.8 times more in occurrence than the left knee ${ }^{5}$. This study found that ACL associated injury was more marked $(19 \%)$ in the age group between 25 and 34 years. Griffin et al. in their study found that of non contact ACL injuries was highest incidence among the age group of 15 to 25 years $^{11}$. This study did not confer with the present study findings. The difference may be due to the fact, that military persons begin their carrier at the age of 18-20 years. Duration of suffering out knee injuries cases; $36.6 \%$ had suffered for 1 to 5 years, $49 \%$ cases suffered for less than $1 \mathrm{yr}$ and $14.40 \%$ cases suffered for more than $5 \mathrm{yrs}$. A study carried out to explore the injuries amongst Bangladesh Armed Forces personnel due to military duties at $\mathrm{CMH}$, Dhaka found that, majority of the respondents $(42.5 \%)$ suffered for a duration of 3-6 months, followed by 6 months to 1 year by (24.4\%), 23.3\% cases suffered for 7-30 days ${ }^{10}$. It was assumed from the study that long term morbidity in present study was less because of available specialized treatment facility at $\mathrm{CMH}$ Dhaka.

\section{Conclusion}

This study revealed that most commonly occurred knee injury was ACL injury. Knee injury mostly affected the earlier age of soldering and training activities than games and sports. Among training activities, mostly jumping in 9 feet ditch, assault course/ bayonet fighting contributed more for the injuries. In games and sports, playing football had contributed the most to the frequency of injuries. Appropriate exercise and conditioning program should be design and implemented in Armed Forces related to the type of training and sports activities. This will help to improve the muscular factors like strength, power, endurance, flexibility and proprioception of the participating musculoskeletal system to prevent the knee injury.

\section{References}

1. Calmbach WL, Hutchens M. Evaluation of patients presenting with knee pain. Part I. History, physical examination, radiographs, and laboratory tests. Am Fam Physician 2003; 68(5):907.

2. Boden $P B$, Griffin $Y L \&$ Garrett EW. Etiology and prevention of noncontact ACL injury. Phys Sport Med 2000; 28(4):53-62.

3. Ruiz AL, Kelly M and Nutton RW. Arthroscopic ACL reconstruction: A 5-9 year follow-up. Knee 2000; 9(3):197-200.

4. Christenson K. Ligaments and muscles stress. Dynamic chiropractic. 2001; 19(7). (para1)[Online].Available at http://www.dynamicchiropractic. com/mpacms/dc/article. php?id=17961 (Accessed 25 November 2017)

5. Kabir H and Mortaza G. Injuries to the menisci in Army. Bangladesh Armed Forces Med J 1984; 9:11-4. 
6. Pathania PV, Kulshreshtha V and Arora CN. Arthroscopic evaluation and management of meniscal injuries of the knee. Med $\mathrm{J}$ of Armed forces of India 2001; 57(2):99-103.

7. Zaman UIC. Knee injuries in Bangladesh Army- A retrospective study. Bangladesh Armed Forces Med J 1988; 12:109-14.

8. Shahidullah M. Pattern of Knee injury due to physical stress amongst the soldiers attending Combined Military Hospital Dhaka. Thesis. Armed Forces Med Institute 2005:75-82.
9. Rahim FS, Chowdhury KMM. and Masud MKA. Evaluation of reconstruction for anterior cruciate ligament insufficiency. Bangladesh Armed Forces Med J 1999; 25: 59-67.

10. Khan NH, Ahmad M, Rahman FN et al. Pattern of injuries amongst Armed Forces personnel received during military activities. JAFMC 2013; 9(2):43-7.

11. Griffin LY, Agel J, Albohm MJ et al. Noncontact anterior cruciate ligament injuries: Risk factors and prevention strategies. J Am Acad Orthop Surg 2000; 8(3):141-50. 